\title{
SPATIOTEMPORAL ANALYSIS ON CO2 EMISSIONS FROM HOUSEHOLDS IN JAPAN
}

\author{
R. Cong *, M. Saito, R. Hirata, A. Ito \\ National Institute for Environmental Studies, Center for Global Environmental Research, 305-8506 Tsukuba, Japan \\ - richao.cong@nies.go.jp
}

ICWG II/III: Pattern Analysis in Remote Sensing

KEY WORDS: Spatiotemporal analysis, Energy consumption, Population census, Building emissions, Household size, GIS

\begin{abstract}
:
Global warming has become worse and worse as the increasing greenhouse gas (GHG) emissions especially by the main contributor carbon dioxide $\left(\mathrm{CO}_{2}\right)$. Thus, clarifying the spatiotemporal patterns of $\mathrm{CO}_{2}$ emissions from residential sector is very important for policy makers. To support the GHG mitigation in local area, this study provides a bottom-up framework that could count the monthly residential $\mathrm{CO}_{2}$ emissions at community level, demonstrated for Japan. A map-based population census is utilized to count the monthly and yearly emissions by combining the statistics data on households with detailed emission intensities. The residential emissions from each census area are estimated and mapped by Geographic Information System. Through the analysis, we proposed the solutions on GHG mitigation and reported the spatiotemporal patterns for residential emissions.
\end{abstract}

\section{INTRODUCTION}

Global warming has become worse and worse due to the increasing greenhouse gas (GHG) emissions. As the largest contributor to global GHG emissions, mitigating carbon dioxide $\left(\mathrm{CO}_{2}\right)$ emissions is urgently needed. Thus, better understanding the spatial distribution and temporal variation of $\mathrm{CO}_{2}$ emissions is important. As reported by IEA, 2018, the $\mathrm{CO}_{2}$ emissions from residential sector account for about $27 \%$ of the global total $\mathrm{CO}_{2}$ emissions in 2016. As the fourth contributor of global $\mathrm{CO}_{2}$ emissions in 2016, about $16 \%$ of Japan`s total emissions are contributed by residential sector (greenhouse gas inventory office of Japan, 2018). These evidences show the residential sector owns a high potential for mitigating the climate change.

To quantify the $\mathrm{CO}_{2}$ emissions from a building, it is available to measure the hourly or daily energy consumption e.g. electricity, city gas, liquefied petroleum gas (LPG), and kerosene. etc which are mainly used for heating, cooling, and lighting in buildings. If enlarging the scale to a city/prefecture or a month/year, accurately clarifying the spatiotemporal patterns of residential emissions become more and more difficult due to the different household sizes and life styles. For this challenge, various studies counted the residential $\mathrm{CO}_{2}$ emissions based on statistics data on energy used for households and downscaled the total emissions by surrogate indices (population or total floor area of buildings) for spatial distribution. For instance, Kannari et al. 2007 have allocated the national residential emissions as the population statistics map at a resolution of $1 \mathrm{~km}$ for Japan, downscaled the annual total emissions to monthly variation as the sample survey on monthly fuel consumption, and divided it for hourly variation as hourly basis supplied city gas amount; Gurney et al. 2012 have allocated the county total annual emissions on the building scale with hourly variation for a large U.S. city based on the total floor area of buildings and hourly basis natural gas supplied data; similar approach has been used by Gately et al. 2017 to downscale the residential emissions at county scale into a $1 \mathrm{~km}$ mesh with hourly variation for north-eastern U.S.; and Bun et al.
2017 downscaled the residential emissions at provincial level in to a $100 \mathrm{~m}$ mesh for Poland with annual emissions based on the maps of population density and others associated with energy use in households. To achieve higher spatial resolution, these studies downscaled the larger scale emissions into smaller scale surrogate indices, resulting in lack of activity data so as not able to support the local climate actions effectively. Cong et al. 2018 have provided an approach to quantify the annual residential emissions for Tokyo at a community level based on the national census and a local survey on energy consumption in households. However, local survey data without temporal variation are not applicable for spatiotemporal analysis in national scale.

In this study, a bottom-up approach is provided for quick mapping the residential $\mathrm{CO}_{2}$ emissions with monthly variation at a community level, exploring solutions for mitigating emissions based on the national sampled emission intensity data for different sizes of households and types of buildings, and analysing spatiotemporal patterns of residential emissions in Japan. For that purpose, the latest population census and national survey on residential emissions are utilized.

\section{METHODOLOGY}

\subsection{Description on the study area and the data}

The region ID, prefecture name, the numbers of households in detached buildings (DB) and in collective buildings (CB), and total numbers of households for all 47 prefectures in Japan are listed on Table 1. To utilize the regional emissions intensity reported by Statistics Japan, 2016, the prefectures are classified by 10 regions. Population census has been conducted at community level every 5 years since 1995 and the latest version for 2015 is utilized in this study. It includes information on inhabitants and households for each census area e.g. numbers of households, inhabitant numbers, occupation, age composition, and types of buildings. To clarify the residential energy use 


\begin{tabular}{|c|c|c|c|c|}
\hline ID & $\begin{array}{l}\text { Prefecture } \\
\text { name }\end{array}$ & $\begin{array}{l}\text { Household } \\
\text { in DBs }\end{array}$ & $\begin{array}{l}\text { Household } \\
\text { in CBs }\end{array}$ & $\begin{array}{c}\text { Numbers } \\
\text { of all } \\
\text { households }\end{array}$ \\
\hline \multirow[t]{3}{*}{ HK } & Hokkaido & $1,304,150$ & $1,131,289$ & $2,435,439$ \\
\hline & Akita & 313,806 & 73,349 & 387,155 \\
\hline & Yamagata & 302,867 & 88,408 & 391,275 \\
\hline \multirow{8}{*}{$\mathrm{TH}$} & Iwate & 355,356 & 133,322 & 488,678 \\
\hline & Aomori & 387,852 & 120,327 & 508,179 \\
\hline & Fukushima & 506,360 & 223,205 & 729,565 \\
\hline & Miyagi & 526,184 & 414,824 & 941,008 \\
\hline & Yamanashi & 241,565 & 88,810 & 330,375 \\
\hline & Tochigi & 550,401 & 211,462 & 761,863 \\
\hline & Gunma & 576,195 & 195,488 & 771,683 \\
\hline & Nagano & 600,901 & 203,522 & 804,423 \\
\hline \multirow[t]{6}{*}{ KT } & Ibaraki & 810,825 & 307,495 & $1,118,320$ \\
\hline & Chiba & $1,410,054$ & $1,192,700$ & $2,602,754$ \\
\hline & Saitama & $1,673,622$ & $1,292,465$ & $2,966,087$ \\
\hline & Kanagawa & $1,697,091$ & $2,266,042$ & $3,963,133$ \\
\hline & Tokyo & $1,999,689$ & $4,690,912$ & $6,690,601$ \\
\hline & Fukui & 215,374 & 63,422 & 278,796 \\
\hline \multirow{4}{*}{ HR } & Toyama & 305,367 & 84,660 & 390,027 \\
\hline & Ishikawa & 316,836 & 135,479 & 452,315 \\
\hline & Nigata & 635,675 & 210,162 & 845,837 \\
\hline & Mie & 535,511 & 182,244 & 717,755 \\
\hline \multirow{5}{*}{ TK } & Gifu & 560,917 & 188,300 & 749,217 \\
\hline & Shizuoka & 956,033 & 470,692 & $1,426,725$ \\
\hline & Aichi & $1,599,229$ & $1,453,564$ & $3,052,793$ \\
\hline & Wakayama & 294,516 & 96,829 & 391,345 \\
\hline & Nara & 355,239 & 173,541 & 528,780 \\
\hline \multirow{6}{*}{ KK } & Shiga & 365,526 & 169,387 & 534,913 \\
\hline & Kyoto & 635,553 & 515,208 & $1,150,761$ \\
\hline & Hyogo & $1,174,150$ & $1,135,135$ & $2,309,285$ \\
\hline & Osaka & $1,626,062$ & $2,290,551$ & $3,916,613$ \\
\hline & Tottori & 155,030 & 60,957 & 215,987 \\
\hline & Shimane & 191,825 & 72,251 & 264,076 \\
\hline \multirow[t]{4}{*}{$\mathrm{CG}$} & Yamaguchi & 408,180 & 188,883 & 597,063 \\
\hline & Okayama & 525,098 & 245,721 & 770,819 \\
\hline & Hiroshima & 689,359 & 518,600 & $1,207,959$ \\
\hline & Tokushima & 215,883 & 89,028 & 304,911 \\
\hline \multirow{6}{*}{ SK } & Kochi & 221,830 & 96,028 & 317,858 \\
\hline & Kagawa & 275,736 & 121,211 & 396,947 \\
\hline & Ehime & 410,896 & 179,633 & 590,529 \\
\hline & Saga & 216,150 & 84,709 & 300,859 \\
\hline & Miyazaki & 325,101 & 136,155 & 461,256 \\
\hline & Oita & 309,235 & 175,670 & 484,905 \\
\hline \multirow[t]{4}{*}{$\mathrm{KS}$} & Nagasaki & 368,016 & 190,048 & 558,064 \\
\hline & Kumamoto & 458,031 & 244,264 & 702,295 \\
\hline & Kagoshima & 501,419 & 220,534 & 721,953 \\
\hline & Fukuoka & $1,000,663$ & $1,193,011$ & $2,193,674$ \\
\hline $\mathrm{ON}$ & Okinawa & 242,941 & 316,254 & 559,195 \\
\hline
\end{tabular}

Table 1. Households in 47 prefectures of Japan classified into 10 regions. HK: Hokkaido, TH: Tohoku, KT: Kanto koshin, HR: Hokuriku, TK: Tokai, KK: Kinki, CG: Chugoku, SK: Shikoku, KS: Kyushu, ON: Okinawa and emissions, Japanese government has conducted a national survey for the period from October 2014 to September 2015 and the monthly results on energy consumption and emissions intensity by energy types, household size, age of inhabitants, gender, income level, building types (DB and CB), and total floor area of buildings are summarized for 10 regions (see classifications on Table 1). In this study, 4 types of energy consumption e.g. electricity, city gas, LPG, and kerosene are made as sources associated with household emissions.

On Table 2, we summarized the yearly emissions intensity per household from October 2014 to September 2015. We could see that the emissions intensity per household in DBs are more than the households with the same inhabitants in CBs except some single person households. If dividing the values by the numbers of inhabitants, we could see the emissions per capita decreases as the inhabitants in the same type of building increases. It implies that promoting residents living in CBs instead of DBs or promoting the single person households for co-housing style could be effective for emissions mitigation.

\begin{tabular}{|l|c|c|c|c|c|c|c|c|}
\hline \multirow{2}{*}{ ID } & \multicolumn{3}{|c|}{$\begin{array}{c}\text { Emissions intensity of } \\
\text { households in DB }\end{array}$} & \multicolumn{4}{|c|}{$\begin{array}{c}\text { Emissions intensity of } \\
\text { households in CB }\end{array}$} \\
\cline { 2 - 9 } & $1 \mathrm{p}$ & $2 \mathrm{p}$ & $3 \mathrm{p}$ & $>3 \mathrm{p}$ & $1 \mathrm{p}$ & $2 \mathrm{p}$ & $3 \mathrm{p}$ & $>3 \mathrm{p}$ \\
\hline $\mathrm{HK}$ & 5.2 & 6.3 & 7.7 & 8.3 & 2.4 & 3.8 & 4.4 & 5.8 \\
$\mathrm{TH}$ & 3.1 & 4.8 & 5.8 & 7.2 & 1.6 & 2.9 & 3.5 & 3.7 \\
$\mathrm{KT}$ & 2.3 & 3.3 & 4.1 & 4.6 & 1.4 & 2.4 & 2.9 & 3.4 \\
$\mathrm{HR}$ & 3.6 & 5.1 & 6.3 & 7.9 & 1.9 & 3.1 & 3.8 & 4.3 \\
$\mathrm{TK}$ & 2.3 & 3.2 & 4.3 & 4.6 & 1.6 & 2.5 & 2.8 & 3.4 \\
$\mathrm{KK}$ & 2.4 & 3.4 & 4.1 & 5.0 & 1.5 & 2.6 & 3.0 & 3.5 \\
$\mathrm{CG}$ & 3.1 & 5.0 & 5.7 & 6.8 & 1.9 & 3.2 & 4.1 & 4.6 \\
$\mathrm{SK}$ & 2.8 & 4.5 & 5.4 & 6.1 & 1.8 & 2.9 & 3.3 & 3.7 \\
$\mathrm{KS}$ & 2.7 & 3.9 & 4.6 & 5.3 & 1.5 & 2.4 & 3.1 & 3.7 \\
$\mathrm{ON}$ & 2.5 & 4.1 & 4.7 & 5.8 & 1.7 & 2.7 & 3.0 & 3.8 \\
\hline
\end{tabular}

Table 2. Yearly emissions intensity for households from Oct 2014 to Sep 2015, p means the person in household (inhabitant), unit: $\mathrm{Mg}$ /household

\subsection{Data processing for visualizing $\mathrm{CO}_{2}$ emissions in households}

To count the residential $\mathrm{CO}_{2}$ emissions, the numbers of households from population census (Statistics Japan, 2015) are multiplied by the monthly emissions intensity per household from a national wide survey (Statistics Japan, 2016). In this study, ArcGIS v. 10.4 is used for counting the emissions. The workflow on visualizing residential emissions is shown in Figure 1. The boundary map on population census is linked with the statistics data on corresponding households. Then the monthly emissions intensities (Statistics Japan, 2016) are allocated as the building types and the household sizes. Through the table calculation tool, we calculate the monthly emissions by energy types, household sizes, and building types for each census area. Finally, the monthly or yearly emissions from these census areas are visualized on map for spatiotemporal analysis. 


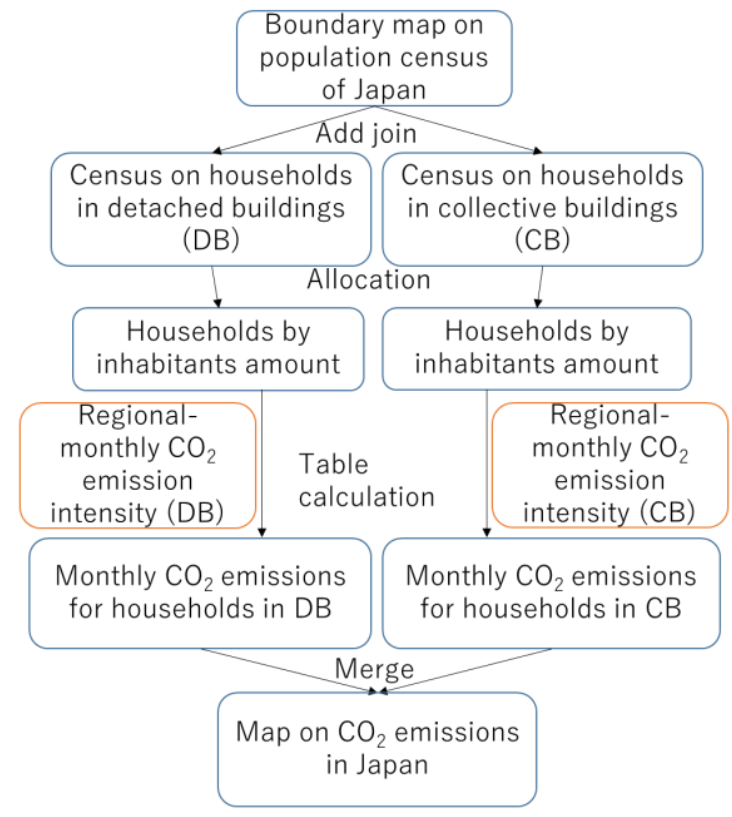

Figure 1. Workflow on visualizing the residential emissions

\section{RESULTS AND DISCUSSIONS}

\subsection{Summary on residential $\mathrm{CO}_{2}$ emissions}

The residential $\mathrm{CO}_{2}$ emissions by energy types and building types of Japan are shown in Figure 2. From October 2014 to September 2015 , the total residential emissions of Japan are about 178 $\mathrm{TgCO}_{2}$ among that the emissions from 4 kinds of energy consumption account electricity $70 \%(124 \mathrm{Tg})$, city gas $13 \%(23$ $\mathrm{Tg}$ ), kerosene $12 \%$ (21 Tg), and LPG 5\% (9 Tg), respectively. To meet the demands of daily life, the increasing use of home appliances and mobile communication devices in households causes those by electricity consumption to be the highest of all energy.

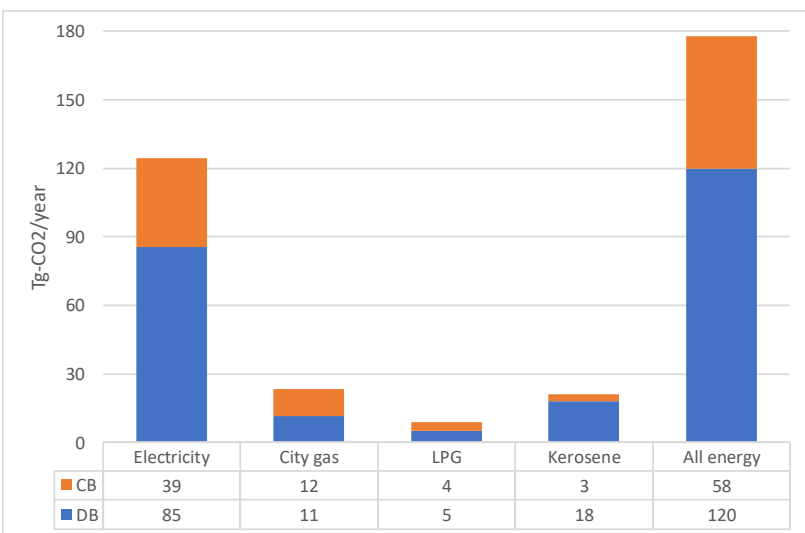

Figure 2. Residential $\mathrm{CO}_{2}$ emissions in Japan by energy types and building types

Focusing on the building types, we found the total emissions from DB households accounted for $68 \%(120 \mathrm{Tg})$ which were about twice of that from CB households $(58 \mathrm{Tg})$. The reasons are that the total floor area of DB per household is larger than that of $\mathrm{CB}$ so that much more electricity consumption is needed for lighting, heating, and cooling. The emissions from electricity consumption by DB households occupies the highest proportion about $48 \%$ ( $85 \mathrm{Tg}$ ), and that by CB households are about $22 \%$

\begin{tabular}{|c|c|c|c|c|}
\hline ID & $\begin{array}{l}\text { Prefecture } \\
\text { name }\end{array}$ & $\begin{array}{c}\text { Emissions } \\
\text { by DB }\end{array}$ & $\begin{array}{c}\text { Emissions } \\
\text { by } \mathrm{CB}\end{array}$ & $\begin{array}{c}\text { Emissions } \\
\text { per } \\
\text { household }\end{array}$ \\
\hline \multirow[t]{4}{*}{ HK } & Hokkaido & 8,569 & 3,933 & 5.13 \\
\hline & Akita & 1,627 & 190 & 4.69 \\
\hline & Yamagata & 1,631 & 238 & 4.78 \\
\hline & Iwate & 1,834 & 348 & 4.47 \\
\hline \multirow{7}{*}{$\mathrm{TH}$} & Aomori & 1,980 & 315 & 4.52 \\
\hline & Fukushima & 2,629 & 585 & 4.41 \\
\hline & Miyagi & 2,745 & 1,047 & 4.03 \\
\hline & Yamanashi & 847 & 208 & 3.19 \\
\hline & Tochigi & 1,954 & 496 & 3.22 \\
\hline & Gunma & 2,028 & 464 & 3.23 \\
\hline & Nagano & 2,127 & 482 & 3.24 \\
\hline \multirow[t]{6}{*}{ KT } & Ibaraki & 2,894 & 712 & 3.22 \\
\hline & Chiba & 4,906 & 2,753 & 2.94 \\
\hline & Saitama & 5,883 & 3,036 & 3.01 \\
\hline & Kanagawa & 5,807 & 5,192 & 2.78 \\
\hline & Tokyo & 6,431 & 9,955 & 2.45 \\
\hline & Fukui & 1,261 & 191 & 5.21 \\
\hline \multirow{4}{*}{ HR } & Toyama & 1,772 & 252 & 5.19 \\
\hline & Ishikawa & 1,784 & 393 & 4.81 \\
\hline & Nigata & 3,676 & 620 & 5.08 \\
\hline & Mie & 1,878 & 429 & 3.21 \\
\hline \multirow{5}{*}{ TK } & Gifu & 2,018 & 459 & 3.31 \\
\hline & Shizuoka & 3,379 & 1,141 & 3.17 \\
\hline & Aichi & 5,608 & 3,419 & 2.96 \\
\hline & Wakayama & 1,055 & 238 & 3.30 \\
\hline & Nara & 1,319 & 433 & 3.31 \\
\hline \multirow{6}{*}{ KK } & Shiga & 1,373 & 412 & 3.34 \\
\hline & Kyoto & 2,253 & 1,169 & 2.97 \\
\hline & Hyogo & 4,269 & 2,714 & 3.02 \\
\hline & Osaka & 5,762 & 5,359 & 2.84 \\
\hline & Tottori & 798 & 187 & 4.56 \\
\hline & Shimane & 974 & 224 & 4.53 \\
\hline \multirow[t]{4}{*}{$\mathrm{CG}$} & Yamaguchi & 2,000 & 569 & 4.30 \\
\hline & Okayama & 2,658 & 741 & 4.41 \\
\hline & Hiroshima & 3,434 & 1,557 & 4.13 \\
\hline & Tokushima & 982 & 236 & 4.00 \\
\hline \multirow{6}{*}{ SK } & Kochi & 970 & 249 & 3.84 \\
\hline & Kagawa & 1,256 & 324 & 3.98 \\
\hline & Ehime & 1,839 & 471 & 3.91 \\
\hline & Saga & 903 & 213 & 3.71 \\
\hline & Miyazaki & 1,291 & 322 & 3.50 \\
\hline & Oita & 1,233 & 416 & 3.40 \\
\hline \multirow[t]{4}{*}{ KS } & Nagasaki & 1,474 & 456 & 3.46 \\
\hline & Kumamoto & 1,867 & 589 & 3.50 \\
\hline & Kagoshima & 1,947 & 511 & 3.40 \\
\hline & Fukuoka & 4,048 & 2,741 & 3.10 \\
\hline $\mathrm{ON}$ & Okinawa & 1,004 & 846 & 3.31 \\
\hline
\end{tabular}

Table 3. Summary on the annual residential emissions for each prefecture by building types $\left(\mathrm{GgCO}_{2} /\right.$ year $)$ and emissions per household ( $\mathrm{MgCO}_{2} /$ household/year) 
(39 Tg). It implies that electricity-based emissions especially from the DB households own the largest mitigation potential of all energy. The city gas-based emissions from CB households (12 $\mathrm{Tg})$ are more than that from DB households $(11 \mathrm{Tg})$. That is because city gas is mainly used in CBs for cooking and heating water for bathing. Much more LPG users residing in DBs caused their emissions by LPG a little more than that by CB households. The kerosene-based emissions from DB households $(18 \mathrm{Tg})$ are much more than that from $\mathrm{CB}$ households $(3 \mathrm{Tg})$. The reasons are that residents in DBs using the kerosene for heating are more than that in CBs due to the gap of the total floor area.

The calculation results on the annual residential emissions by building types and emissions per household for each prefecture are listed on Table 3. We found that the emissions from households in DBs of Hokkaido $(8,569 \mathrm{Gg})$ were the most of all and that of Tottori were the least of all $(798 \mathrm{Gg})$. The emissions from households in CBs of Tokyo $(9,955 \mathrm{Gg})$ are most of all and that of Tottori were the least of all $(187 \mathrm{Gg})$. Three prefectures with the least annual emissions per household are Tokyo (2.45 $\mathrm{Mg}$ per household per year), Kanagawa (2.78 Mg per household per year), and Hokkaido (5.13 $\mathrm{Mg}$ per household per year). The prefectures with top 3 emissions per household are Fukui (5.21 $\mathrm{Mg}$ per household per year), Osaka (2.84 Mg per household per year), and Hokkaido (5.13 Mg per household per year).

\subsection{Spatial distribution on residential $\mathrm{CO}_{2}$ emissions}

To discuss the spatial distribution of the residential emissions, we listed the emission maps for all 10 regions in Figure 3. From the emissions map of Hokkaido, we found that most of areas emitted less than $10 \mathrm{Gg} \mathrm{CO}_{2}$ in this period (in green). Through the attribute table, we found each of 9 areas emitted more than $10 \mathrm{Gg}$. There are 6,547 residents from 1,699 DBs and 1,150 CBs live in the area with the highest emissions (about 15.6 Gg). On the emissions map of Tohoku region, we found that some higher emissions areas located on the northern parts belonging to Aomori (in orange and red). There are 49 areas which emitted more than $10 \mathrm{Gg}$. The highest emission area of this region located in Aomori (about 27.4 Gg) and 15,000 residents from 4,726 DBs and $719 \mathrm{CBs}$ live in this area. It is also the census area with the highest emissions in Japan. On the emissions map of Kanto koshin region, we found that some higher emissions areas concentrated around Tokyo Bay (on the south and right part). There are 75 areas that emitted more than $10 \mathrm{Gg}$ and 3 areas (from Saitama, Kanagawa, and Tokyo, respectively) emitted more than $20 \mathrm{Gg}$. The area with the highest emissions of this region located in Saitama (about 21.6 Gg) with 16,496 residents from 4,924 DBs and $1,739 \mathrm{CBs}$. On the emissions map of Hokuriku region, most of areas emitted less than $10 \mathrm{Gg}$. There are 2 areas belongs to Niigata emitted more than $10 \mathrm{Gg}$ and the area with the highest emissions of this region located in Niigata (about $10.8 \mathrm{Gg}$ ) with 5,717 residents from 1,016 DBs and 2,793 CBs.

From the emissions map of Tokai region, there are 37 areas that emitted more than $10 \mathrm{Gg}$. The highest emissions area of this region located in Shizuoka (about $20.3 \mathrm{Gg}$ ) where 15,642 residents live in 4,232 DBs and 2,437 CBs. On the emissions map of Chugoku region, we found that some higher emissions areas distributed near the south edge of this region. There are 43 areas that emitted more than $10 \mathrm{Gg}$ and 2 areas (from Okayama, and Hiroshima) emitted more than $20 \mathrm{Gg}$. The area with the highest emissions of this region located in Okayama (about $22.3 \mathrm{Gg}$ ) which owns 12,657 residents from 4,075 DBs and 404 CBs. On the emissions map of Shikoku region, there are 38 areas that emitted more than $10 \mathrm{Gg}$. For the highest emissions area of this region located in Kochi (about $20.0 \mathrm{Gg}$ ), 11,921 residents live in
3,444 DBs and 1,670 CBs. From the emissions map of Kinki region, there are 29 areas that emitted more than $10 \mathrm{Gg}$. The higher emissions located on the left central area (in red). The area with the highest emissions of this region located in Osaka (about $17.6 \mathrm{Gg}$ ) which owns 16,114 residents from $108 \mathrm{DBs}$ and 6,281 CBs. For Kyushu region, we found 31 areas emitted more than $10 \mathrm{Gg}$. The highest emissions area of this region $(18.0 \mathrm{Gg})$ located in Kagoshima with 11,864 residents from 3,667 DBs and $1,275 \mathrm{CBs}$. From the emissions map of Okinawa, we found that most of areas emitted less than $10 \mathrm{Gg} \mathrm{CO}_{2}$ in this period. Through the attribute table, we found there were 7 areas emitted more than $10 \mathrm{Gg}$. For the highest emissions area of Okinawa (about 13.9 $\mathrm{Gg}$ ), there are 10,120 residents living in 1,855 DBs and 2,518 CBs.

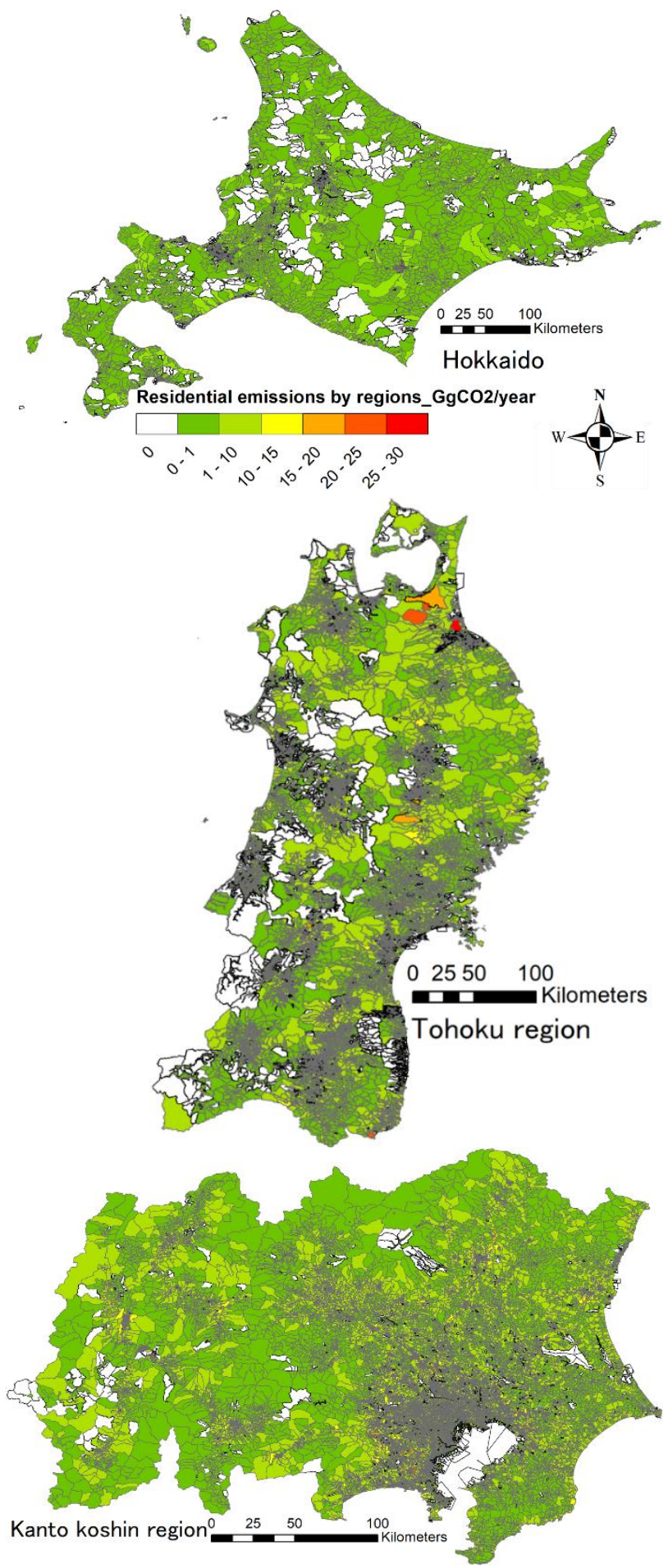



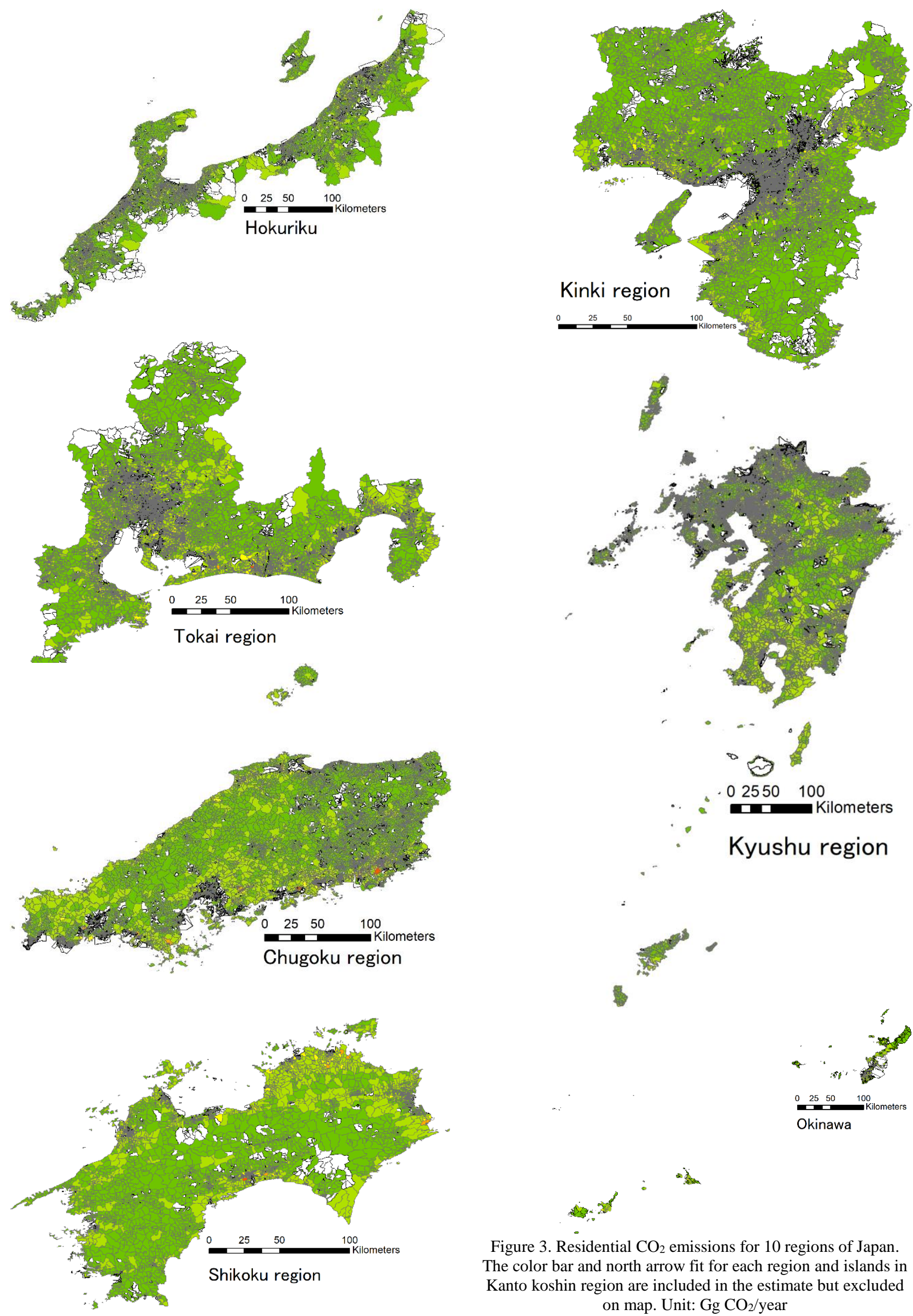

Figure 3. Residential $\mathrm{CO}_{2}$ emissions for 10 regions of Japan. The color bar and north arrow fit for each region and islands in Kanto koshin region are included in the estimate but excluded on map. Unit: $\mathrm{Gg} \mathrm{CO}_{2} /$ year 


\subsection{Monthly variation on residential $\mathrm{CO}_{2}$ emissions}

The monthly variation on residential emissions by energy types of Japan from October 2014 to September 2015 are shown in Figure 4. The emissions by electricity consumption meet two peaks in January and August. The reasons are that residents increased electricity consumption for heating in winter and cooling in summer to the top in these months. We found the emissions by kerosene consumption sharply increased from November, a peak started from December to February, and sharply decreased from March. The reason is that kerosene consumption for heating in these cold months varied as the temperature change. The emissions by city gas and LPG increased from November until a peak occurred in January. That is mainly caused by Japanese cooking style that residents prefer to make hot pot in colder days and cook much food to celebrate the Spring Festival around $1^{\text {st }}$ January.

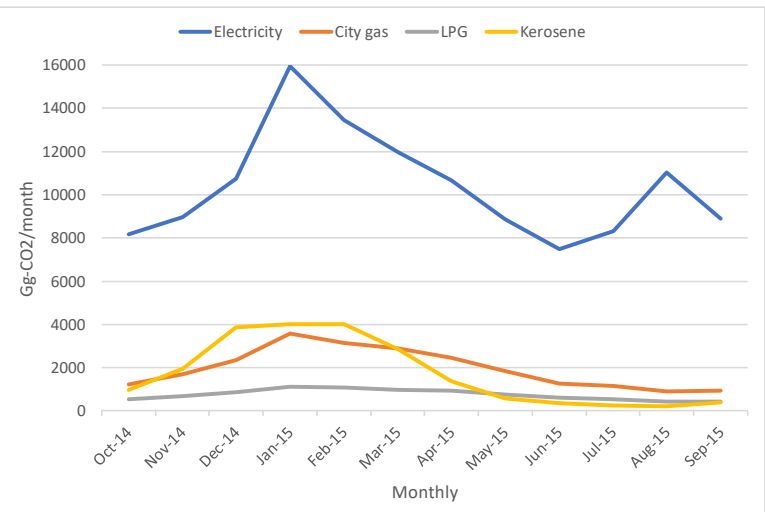

Figure 4. Monthly variation on residential $\mathrm{CO}_{2}$ emissions of Japan by energy types from October 2014 to September 2015

To explore the relationship between the residential $\mathrm{CO}_{2}$ emissions and temperature, we chose three regions (Northernmost: HK region, central Japan: KT region, and Southernmost: ON region) to analyse the monthly variation on the monthly mean temperature and the total emissions in each region. The monthly mean temperature data were observed and reported by the Japanese government (Japan Meteorological Agency, 2019). The results are shown in Figure 5.

From Figure 5a, we found that the residential $\mathrm{CO}_{2}$ emissions met a peak when the mean temperature reached the lowest in cold season of Hokkaido region. It is mainly caused by the increased usage of the air conditioners, fuel consumptions for heating and the cooking. The residential $\mathrm{CO}_{2}$ emissions were stable even the temperature changed in warm season. Because the temperature in these months are not high enough to use the air conditioner for cooling. As the result for Kanto region shown in Figure 5b, the trend on emissions and temperature in cold season was similar with that in Hokkaido region. Another peak was found in warm season of Kanto region due to the increased use of the air conditioner in these months.

From Figure 5c, a different trend on emissions and temperature was found in Okinawa region with the above two regions. The peak of residential $\mathrm{CO}_{2}$ emissions in warm season are higher than that in the cold season. That is because the temperature is higher than $15{ }^{\circ} \mathrm{C}$ in each month in this region. As a result, there is less use of air conditioner and fuel consumptions for heating in cold season with lower residential $\mathrm{CO}_{2}$ emissions. The residential $\mathrm{CO}_{2}$ emissions are the lowest in December in this region, with a monthly mean temperature about $18{ }^{\circ} \mathrm{C}$.

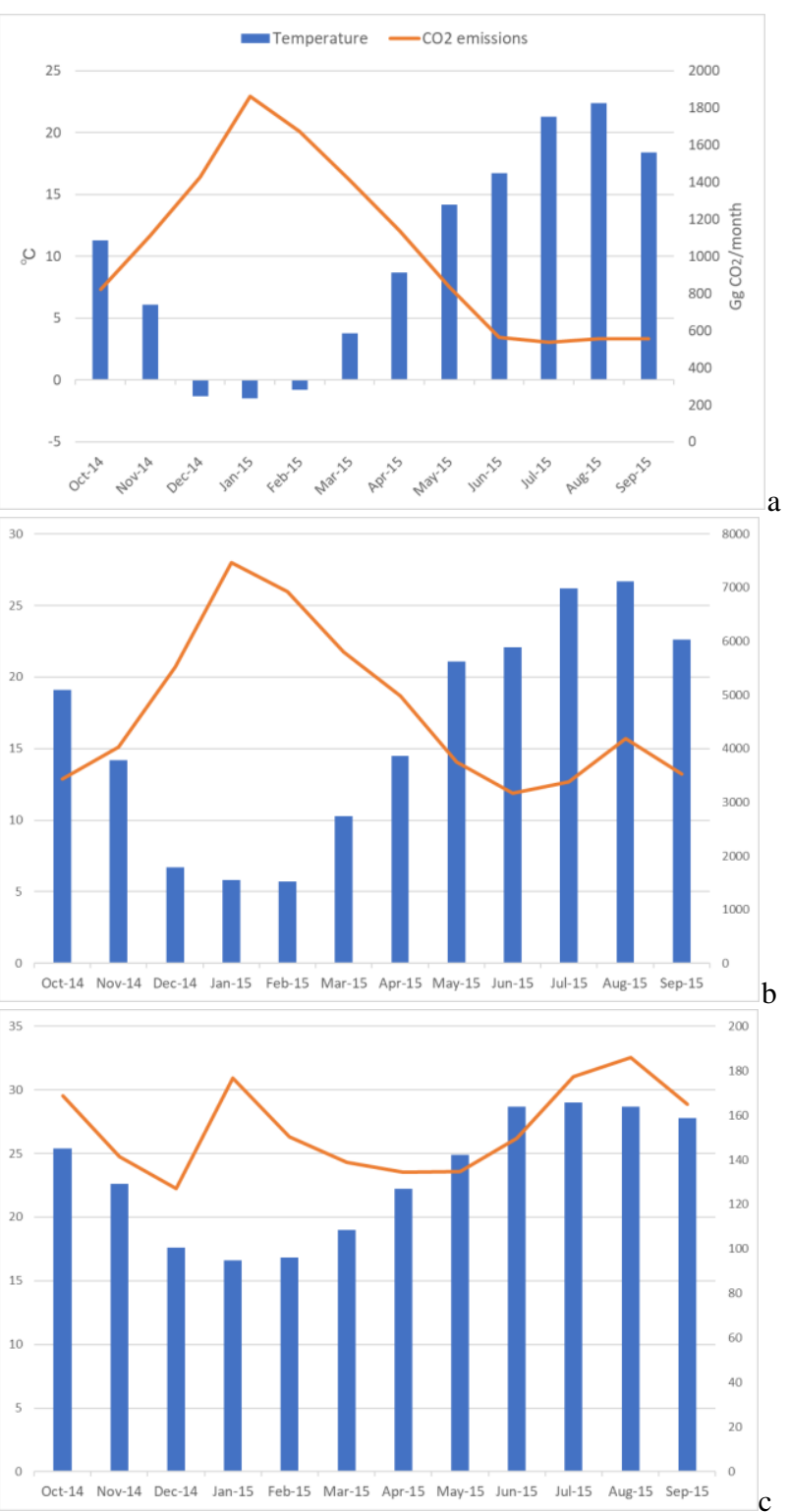

Figure 5. Monthly variation on residential $\mathrm{CO}_{2}$ emissions and monthly mean temperature from October 2014 to September 2015 in Hokkaido region (a), Kanto region (b), and Okinawa region (c). Referring to the left y-axis, the blue vertical bar represents monthly mean temperature $\left({ }^{\circ} \mathrm{C}\right)$, and the right y-axis reflects the monthly total residential $\mathrm{CO}_{2}$ emissions $(\mathrm{Gg}$

$\mathrm{CO}_{2} /$ month) in this region shown by the orange line.

\subsection{Compare with other results}

To check the estimated emissions, we summarized our estimate of emissions from city gas, $\mathrm{LPG}$, and kerosene as fossil fuel $\mathrm{CO}_{2}$ emissions $\left(54,945 \mathrm{Gg}-\mathrm{CO}_{2}\right)$ and compared them with those for $2015\left(55,397 \mathrm{Gg}-\mathrm{CO}_{2}\right)$ counted by top-down approach from the greenhouse gas inventory office of Japan. Our result is about $0.8 \%$ less than their result which suggests that our estimates are reasonable ones in this stage.

In addition, we extracted our result on fossil fuel $\mathrm{CO}_{2}$ emissions for Tokyo from October 2014 to September $2015(6,453 \mathrm{Gg})$ and compared it with the emissions for Tokyo in $2014(5,826 \mathrm{Gg})$ estimated by Cong et al. 2018. The differences for our result of $10.8 \%$ more than theirs are mainly caused by the changed 
numbers of households in different periods and the energy consumption intensities from different surveys we used.

\section{CONCLUSION}

In this study, we provided a bottom-up approach for quick mapping the residential $\mathrm{CO}_{2}$ emissions with monthly variation for each community in Japan, found solutions for mitigating emissions focusing on the building types and household size, analysed the spatiotemporal patterns for annual emissions, explored the relationship between the emissions and the climate conditions, and validated our estimate with other results. The conclusions are as follows:

We find that promoting residents living in CBs instead of DBs or promoting the single person households for co-housing style could be effective for emissions mitigation.

From October 2014 to September 2015, the total residential emissions of Japan are about $178 \mathrm{Tg}-\mathrm{CO}_{2}$ and $70 \%(124 \mathrm{Tg})$ of them are caused by electricity consumption. Focusing on the emissions by building types, the total emissions from DB households accounted for $68 \%(120 \mathrm{Tg})$ which are about twice of emissions from CB households $(58 \mathrm{Tg})$.

We report the spatial distribution on residential emissions for all 10 regions of Japan and give the reasons for the peaks of emissions in a year caused by each kind of energy.

The residential $\mathrm{CO}_{2}$ emissions change as the variation of temperature and show a regional characteristic in Japan.

Through the comparison with other results, our estimate shows good performance.

We believe that this study could help the policy makers on local carbon management. As a challenge, we plan to develop a bottom-up approach for counting the residential emissions at by building level based on the remote sensing data e.g. the digital surface model, include other sectoral emissions and make inverse analysis so as to validate with the observation by satellites or carbon flux towers.

\section{REFERENCES}

Bun, R., Nahorski, Z., Horabik-Pyzel, J., Danylo, O., See, L., Charkovska, N., Topylko, P., Halushchak, M., Lesiv, M., Valakh, V., Kinakh, V., 2018. Development of a high-resolution spatial inventory of greenhouse gas emissionsfor Poland from stationary and mobile sources. Mitigation and Adaptation Strategies for Global Change, 1-28.

Cong, R., Saito, M., Hirata, R., Ito, A., Maksyutov, S., 2018. Visualization on fossil-fuel carbon dioxide $\left(\mathrm{CO}_{2}\right)$ emissions from buildings in Tokyo metropolis. ISPRS Ann. Photogramm. Remote Sens. Spatial Inf. Sci., IV-4, 21-25. doi.org/10.5194/isprs-annals-iv-4-21-2018.

Gately, C.K., Hutyra, L.R., 2017. Large uncertainties in urbanscale carbon emissions. Journal of Geophysical Research: Atmospheres, 122(20), 11-242.

Greenhouse gas inventory office of Japan. The GHG emissions Date of Japan (1990-2016), 2018. http://wwwgio.nies.go.jp/index.html. (1 August 2018).

Gurney, K. R., Razlivanov, I., Song, Y., Zhou, Y., Benes, B., Abdul-Massih, M., 2012. Quantification of fossil fuel $\mathrm{CO}_{2}$ emissions on the building/street scale for a large US city. Environmental science \& technology, 46(21), 12194-12202.

IEA. $\mathrm{CO}_{2}$ emissions from fuel combustion 2018 overview. 2019. https://www.iea.org/statistics/co2emissions/. (1 March 2019).

Japan Meteorological Agency. The record on past temperature in Japan. 2019.

https://www.data.jma.go.jp/obd/stats/etrn/index.php. (15 June 2019).

Kannari, A., $\quad$ Tonooka, Y., $\quad$ Baba, T., Murano, K., 2007. Development of multiple-species $1 \mathrm{~km} \times 1 \mathrm{~km}$ resolution hourly basis emissions inventory for Japan. Atmospheric Environment, 41(16), 3428-3439.

Statistics Japan. 2015 Population Census (in Japanese). 2017. http://www.stat.go.jp/english/data/kokusei/index.html.(1 April 2018).

Statistics Japan. Investigation on residential energy use for counting the $\mathrm{CO}_{2}$ emissions from households in 2014-2015(in Japanese). 2019. https://www.e-stat.go.jp/en.(10 March 2019). 